\title{
Are Early Malaria Case Detection and Treatment the Key?
}

\author{
Atef Ali Kloub* \\ The National Center for Malaria Control \& Vectors, United Arab Emirates
}

*Corresponding author: Atef Ali Kloub, Training Team Head \& Coordinator Health education, M:0564477982, The National Center for Malaria Control \& Vectors, P.O. Box: 5773 Sharjah/ United Arab Emirates

\begin{tabular}{|c|c|}
\hline ARTICLE INFO & ABSTRACT \\
\hline $\begin{array}{l}\text { Received: March 13, } 2019 \\
\text { Published: March 21, } 2019\end{array}$ & $\begin{array}{l}\text { Malaria is one of the most serious health problems facing the world today and is } \\
\text { one of the most common diseases affecting humans. Malaria causes more than } 400,000\end{array}$ \\
\hline $\begin{array}{l}\text { Citation: Atef Ali Kloub. Are Early Ma- } \\
\text { laria Case Detection and Treatment the } \\
\text { Key?. Biomed J Sci \& Tech Res 16(2)- } \\
\text { 2019. BJSTR. MS.ID.002824. }\end{array}$ & $\begin{array}{l}\text { 2018). Unfortunately, 92\% of deaths occur in children under the age of five years and } \\
\text { in Pregnant women. Female Anopheles Mosquitoes (some species) are the main vector } \\
\text { for malaria disease transmission from the infected patients with malaria plasmodium } \\
\text { parasites to the other healthy persons, so it is essential to learn more about malaria and } \\
\text { find effective methods assist to reduce the amount of infections and control those cases } \\
\text { which are nominated to be complicated cases then they may be die. Under the available } \\
\text { facts are known about malaria, this target is simply could be achieved if we are following } \\
\text { procedures are employed to serve the patient, therefore many of methods and proce- } \\
\text { dures which are used now in malaria lab diagnostic must be improve and modify and this } \\
\text { is under responsibility of physicians first then the lab technologists who they must have } \\
\text { skills to achieve all what the physicians request them for malaria tests. }\end{array}$ \\
\hline
\end{tabular}

\section{Biography}

Mr. Atef Ali spent 40 years, experience working in Malarial field. He has got the chance to work in both malaria laboratory departments, the entomological and the parasitological lab. Mr. Atef is a member of the malarial technologists team who participated in the UAE national program for eradication malaria disease and assisted in the success of the program. Which had been certified by WHO among announced the UAE is free of malaria transmission. $\mathrm{He}$ is a trainer and a lecturer in malaria field and has got his own training programs, one for the medical laboratory technologists, providing a practical training for the microscopy diagnosis of Malaria parasites, while the other is opened for all technicians to learn the microscopy skills for identification the Anopheles species of larvae and adult mosquitoes, and both of training courses are confirmed by the CME department at MOH.-UAE. Mr. Atef Ali published two manual guide booklets for trainees in both aspects, the entomology and parasitology in malaria in addition for many articles and researches were published in some scientific journals and Al Geizerah university at Sudan, also he prepared two guide booklets for the trainees joining the training courses in both of malaria aspects the parasitology and ntomology.

Mr. Atef Ali also lecturer on Malaria and other vector borne diseases for various society groups and joined many medical conferences and currently will participate one on Dubai-UAE on 6th November 2017 as a first speaker and is given the session chair. Also has received an invitation to participate Global Experts Meeting on Infectious Diseases “ (Infectious Diseases Meeting 2018) during September 3-4, 2018 at Tokyo, JAPAN.

This expression even if it is modified to become the early detection and accurate correct diagnosis in addition to an effective treatment is the key, I will still disagree and criticize this expression and considered it as inaccurate because of the following facts: During 40 years of work in malaria field, I was dealing with a lot of malaria cases which have been detected early and their laboratory diagnosis was true. and have been given effective treatment, although they have entered in complications (due to malaria and not for other reasons), some of which have ended with the death. 
This leads for thinking about the existence of a real key or keys which will encourage us to know what these keys are? I think that the determination of parasitic infection intensity should be included in the first request directed to the laboratory by the physician who investigates the result of laboratory testing of malaria to be the result as a standard to compare with the following examination requests to determine the patient's response to treatment in a timely manner in which it can be controlled because the time factor is very important in Malaria cases, especially falciparum, so that what it may be possible now may become impossible after hours. What is exactly, the meaning of the accurate laboratory test for malaria? The precise and correct meaning of the laboratory diagnosis of malaria could be summarized as follows:

a) Specifying the type of malaria parasite detected microscopically.

b) Describe all stages of malaria plasmodium parasites are seen in the in the examined blood sample and determine their density.

c) Use appropriate parasite counting methods (percentage of infected red blood cells, number of parasites / cubic mm.

In contrast, the physician should understand that the rapid methods for malaria parasite diagnosis unable to achieve what is required. Their alert avoiding using the rapid tests method which are unable to determine the parasite's stages or to determine the parasitic infection intensity should be applied in the malaria test requests.

\section{ISSN: 2574-1241}

DOI: 10.26717/BJSTR.2019.16.002824

Atef Ali Kloub. Biomed J Sci \& Tech Res

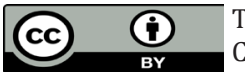

This work is licensed under Creative Commons Attribution 4.0 License

Submission Link: https://biomedres.us/submit-manuscript.php
It is very essential for the doctor to know the meaning and seriousness of the presence of schizonts and late trophozoites stages in $\mathrm{f}$ falciparum malaria cases which appears only in advanced cases and their presence is indication that the patient passing a serious condition needs attention and may need to transfer blood or sometimes exchange blood. So, the malaria report results for example as:

a. P.f positive. is correct but not accurate.

b. P.f positive $\mathrm{r}++++\mathrm{tr}+\mathrm{sch}+$. is accurate, but not enough.

Parasitemia density must be estimated like: 15\% of RBCs are parasitized or 200,000 parasites/ $\mu$ l. So, I believe that scientific logic will consider that determine the severity of infection which has only one method to represent about it (parasite count) is being the fact and the real key for the malaria case by which it is easy to monitor malarial case if it is responding for treatment or not in the valuable and suitable time in which there are more available choices under physicians hands, therefore these same choices may be become useless after a short time. It is clear that it is possible to reduce the death incidence of malaria and prevent the occurrence of many of them by using simple and easy methods which not need specific skills to achieve, but a good knowledge and background of malaria issue and take into account that the duties of different medical specialties that serve the case of malaria are complementary to each other. 